\title{
An Elaboration on Measures to Promote Institutional Innovation, Transformation, and inclusiveness to Enhance Public Service Delivery
}

Gilbert Roland*

BSc (Hons), MPH Ministry of Healh and Quality of Life, MAURITIUS

\begin{abstract}
In recent years, many governments have focused on the development of innovative ways to improve the delivery of public services. There have been several international conferences and forums by world leaders seeking to improve the state of their countries' public administration. Mauritius is no exception. An improvement of governance and public service delivery will make significant contributions towards the achievement of Millennium Development Goals. This paper analyses the measures Mauritius can adopt to promote institutional innovation, inclusiveness, and transformation which shall enhance public service delivery. The analysis occurs through a focus on the current state of public service delivery, what is being done, and what the country can do in the future.
\end{abstract}

Keywords: Public service; Governments; Public administration; Delivery

\section{Introduction}

Mauritius is an African country that has developed into one of the top economic reformers in the continent. According to the African Development Bank [1] it has successfully become a Middle-Income Country from previously being a Low-Income Country. The progress of the country can be attributed to the existence of strong institutions, political stability, and an environment conducive for economic growth. With less than $1 \%$ of its people viewed as poor, Mauritius can adopt relevant policies and strategies to enable it to become a High-Income Country. Its history of political stability and good governance can be attributed to its leaders' focus on promoting the country's development vision, social inclusion, sustaining democratic values, and good governance. Before a discussion of the measures Mauritius can adopt to improve institutional innovation, transformation, and inclusiveness, it is vital to analyze what is already It will ensure. It exposes us to the progress the country has already made and how much more can be done to improve public service delivery.

\section{Current State of Public Service Delivery}

The government is focused on improving the lives of its people through effective public service delivery. It hopes to transform the nation into an economically vibrant, environmentally sustainable, and innovative country through a focus on high skills and technology, global connectivity, and infrastructure [2]. Public service delivery is influenced mainly by increasing fiscal pressures, technology through ICT, and citizen expectations [3]. According to the President of the Republic of Mauritius [2], Mauritius received a Public Service Excellence Award because of its focus on innovation and creativity. Through "Achieving the Second Economic Miracle-Vision 2030", it encourages various organizations to adopt innovative and strategic approaches to allow the provision of more citizen-centric services. Organizations that adopt the reform policies and strategies are rewarded. Its public services focus on improving the quality of life, strengthening democracy, and accelerating social integration by guaranteeing the independent functioning of its various institutions. It considers demands, demography, budget, and other factors to ensure sustainable outcomes [4]. The provision of exemplary governance and public service delivery focuses on the following principles:

1. Judicious and responsible consumption of public funds.

2. Open bidding and procurement to eliminate corruption and fraud.
3. Reforming the public-sector institutions to promote efficiency, productivity, and quality Service.

4. Meritocracy-based and transparent recruitment and appointment policy.

5. Adopting a zero tolerance against crime and violence.

6. Ensuring access to information and the expansion of democratic space.

7. Liberating the society from the limitations of corruption, nepotism, favoritisms, and political.

Concerning inclusiveness, the government has ensured the transformation of the public service sector to cater for the needs of the vulnerable more effectively. Social inclusion has improved through an increase in pension payments to the elderly, physically handicapped, widows, orphans, and other citizens receiving social [2]. The nation focuses on ensuring citizens' satisfaction with public facilities and services. It must look to the future by considering the skills and attitudes required and the aspirations that shape the quality, experience, and delivery of public service [5]. The government has also made efforts to revitalize the civil service [6]. Through the code of ethics to regulate the central government officers' duties and responsibilities, professional behavior and political impartiality are promoted. There is also a focus on integrity, accountability, efficiency, and the provision of responsive services

Regarding performance and management, civil servants are trained to exercise dynamism, innovation, entrepreneurship, and flexibility in service provision. Their operations must remain within the defined strategies, priorities, and guidelines. Other values the government focuses on developing in them include; integrity, efficiency, merit, leadership, equity, and productivity. It focuses on developing and

*Corresponding author: Gilbert Roland RN, BSc (Hons), MPH Ministry of Healh and Quality of Life, MAURITIUS, Tel: +23058855468, E-mail: groland642@gmail.com

Received July 14, 2017; Accepted July 24, 2017; Published July 28, 2017

Citation: Roland G (2017) An Elaboration on Measures to Promote Institutional Innovation, Transformation, and inclusiveness to Enhance Public Service Delivery. Review Pub Administration Manag 5: 220. doi:10.4172/2315-7844.1000220

Copyright: ( 2017 Roland G. This is an open-access article distributed under the terms of the Creative Commons Attribution License, which permits unrestricted use, distribution, and reproduction in any medium, provided the original author and source are credited. 
sustaining organizational environments that nurture innovation and coping with current trends. The ministries and departments work in concert with parastatals, decentralized authorities, central agencies, state companies, and other partners. The public sector is constantly improving itself to cater for the proactive, progressive, demanding, and aggressive society. It ensures a flexible chain of command in its vertical and horizontal management [6].

About the services and facilities, the sector focuses on being responsive to the needs of the people through quality and timely services. It seeks new strategies to eliminate insensitivity, rigidity, red tape, and responsiveness. The emerging demands and challenges of the contemporary society can be eliminated through a reduction in over-regulation. More needs to be done with regard to this aspect. The right strategies can help in dealing with fiscal constraints public service will encounter [7]. Concerning e-governance, it is a new concept of administration adopted by Mauritius to improve access to public services through electronic platforms. It has helped in restructuring archaic procedures and getting rid of dysfunctional systems in public administration. The people can renew licenses and permits online. It also reduces the probability of corruption by officials, citizens, and intermediaries. The government can improve its use of e-governance for maximum efficiency [8]. The government must ensure adequate provision for the service delivery needs of the nation without compromising its unfavorable status [9]. Various strategies can be adopted by the Mauritian government to ensure an improvement of the quality of public service delivery. According to the President of the Republic of Mauritius [2], the government launched information management systems for its parastatals. Workshops allowed the sensitization of officials and employees on the importance of reforms and effective management of resources. An improvement of service delivery and management can be innovative through innovative thinking and the generation of governance reforms. The following section discusses the strategies and policies with regard to innovation, inclusiveness, and transformation.

\section{Measures to Improve Public Service Delivery}

Mauritius can adopt a variety of measures to improve its public service delivery through a focus on innovation, inclusiveness, and transformation. It can emulate the strategies adopted by other countries worldwide. Globally, many governments have realized the need to engage citizens in governance thus improving sustainable development. Thus, the adopted strategies focus on improving awareness and handling of various issues relating to public service. The government must consider a range of alternatives in the delivery of services and infrastructure to its people. It touches on every aspect of the people's life; social, political, and economic. Some of the measures include:

\section{E-Governance}

Although an e-government system already exists, there is a need for its expansion and improvement to maximize the quality of public service delivery. Changes to the system should focus on how the e-government strategies and policies can be created and used to promote efficient administration. According to United Nations [10], e-government strategies and policies can be used in promoting more effective, accountable, transparent, citizen-centric, and participatory public administration. Its adoption has a profound impact on economic and social development. It is a perfect example of how Mauritius can use innovation in improving public service delivery. Through online public services, the government can minimize the occurrence of corruption, thus improving transparency. It is also cost-effective, participatory, and efficient. The e-government platform will allow the government to communicate better with its people and understand their problems. Knowing the challenges helps in the adoption of innovative means to deal with them and use ICT to deliver public services.

Through international conferences, Mauritian leaders can interact with leaders from other nations, share best practices, and adopt effective means of promoting e-governance. The transformation strategies will involve an analysis of existing e-governance policies and make improvements through the adoption of new strategies and policies. The practical implementation of the policies and strategies will guarantee a positive change in the quality of public service delivery. Among other factors, this will involve the adequate training of civil servants at all levels to acquire the knowledge and skills necessary for the implementation of the new e-governance strategies and policies. It will help in preventing public service mistakes and crises that have a disastrous impact on the lives of people [11].

Concerning inclusiveness, the processes must ensure adequate consideration and opportunities for women, the disabled and other citizens who may be at a disadvantage. Through an improvement of public service delivery, women can be empowered. A public administration the approach that integrates a gender approach promotes gender equality, the rule of law, democracy, and the value of human rights. All citizens must have equal opportunities to participate in the decision-making processes and benefit from the e-governance changes. Mauritius can use e-governance as a tool to solve its modernday challenges through the collective effort of all citizens.

\section{Transformation of the Public Sector}

The quality of public service delivery can be improved through a complete change of the public sector. According to Deloitte [9], the government can partner with relevant organizations to identify its needs and come up with sustainable solutions. OECD [12] shows that partnerships between the government and the public can improve the delivery of public services. It will allow the adoption of creative policy responses to help deal with times of fiscal constraints. Although the active involvement of citizens is relatively new in many countries, Mauritius can utilize it and benefit from cost reductions, improved user satisfaction, and better service quality. Mauritius can benefit from the approach through a focus on five broad avenues of change including;

1. Engaging in strategies to cut costs, improve the public's faith in the government, and reshape public service expectations.

2. Creation of employment opportunities and an improvement of the country's competitiveness in the global arena.

3. Transformation of major policy areas such as the education and health sector.

4. Ensuring departmental operations adopt more innovative and technologically advanced ways of catering for emerging needs.

5. Ensuring the effective implementation of government reform programs.

\section{Price Waterhouse Coopers' Five-Step Strategy}

Another measure that can be adopted by Mauritius in improving public service delivery is the adoption of the five-step strategy [13].

\section{Customer-centricity}

The transformation process should focus on understanding the needs of Mauritians. It involves a consideration of diversity issues, the 


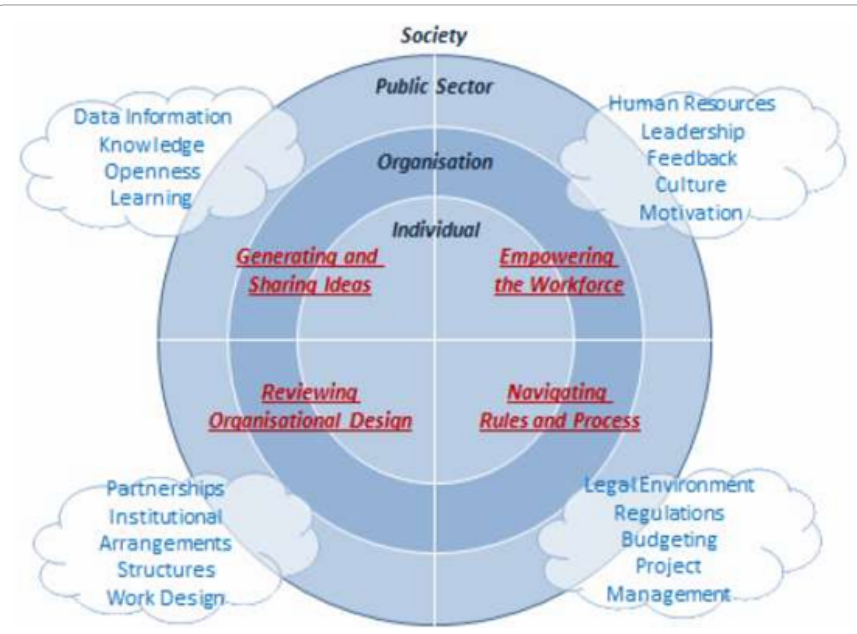

Figure 1: A PSI framework: Sourced from 'Innovating the public sector: From ideas to impact' OECD Conference "Paris, 12-13 November 2014.

cost of services, demographics, attitudes, and behaviors. The country can create multiple delivery channels aligned with the needs.

\section{A connected government}

The hierarchical structures should be aligned and focus on common customer-centric visions processes, outcomes, and information flow. It can be done through an enabling legal and policy framework (Figure 1).

\section{Building capacity}

It involves empowering the various institutions through multi-level transformations. Changing the way of the sector acts and thinks focuses strategy, leadership, culture, organizational design, and the people's capacity training.

\section{Delivering the promise}

It involves realizing the benefits of the implemented strategies. It requires an understanding of the sector's goals and how to achieve them. Technology must be incorporated and regular evaluation of the strategies done.

\section{Continuous innovation}

It involves ongoing efforts to improve the policies and strategies. It helps in identifying and adopting new best practices to drive innovation. Mauritius can take advantage of benchmarking to learn from other nations.

\section{Implementing the Public Service Innovation Framework}

According to Daglio et al. [14], the government can take advantage of its structured organizational environment to support innovation. Through the framework below, it can consider the impact of various organizational attributes (rules, structures, processes, technologies, and culture) on innovation in various institutions.

It is a significant step towards the identification and analysis of various factors that influence innovation in the public sector. It is not rigid thus can be adjusted to fit the unique context of Mauritius and any changes that may occur in the future. The circles in the diagram represent the levels of analysis. The center is occupied by individual innovators while the level that follows represents the various organizations in which the individuals carry out their innovative practices. The third circle is a representation of the public sector in Mauritius; this consists of various organizations. The outermost circle represents the larger society which partners with the public sector to innovate.

The four quadrants are a presentation of organizational attributes that influence innovation in the public sector; generation and sharing of ideas, workforce empowerment, navigating processes and rules, and a review of the organizational design. A consideration of the factors will ensure effective implementation of innovative strategies. The sector will realize its goals of improving the efficiency of its service provision, providing value for money and reducing the costs involved in service provision.

\section{Improving Meritocracy}

Through appropriate transformational approaches, the nation can improve meritocracy in the public service delivery sector. According to Dukhira [6], the promotion and recruitment of employees in the sector have not been judicious for years. At various levels of the Mauritian public sector, officers have been appointed without adherence to scientific considerations. Through strategies focused on integrity, the sector can ensure only the appointment and promotion of eligible and qualified officers without favoritism or corruption. It must ensure no applicants are disadvantaged with regard to sex, race, community, religion, culture, class, caste, family or status.

\section{Eradicating Barriers to Implementation}

Developing strategies for improving public service is not enough. Mauritius must also identify some of the factors that can hinder the implementation of the above strategies. It will ensure no hindrance to the measures. A review of evidence has shown the failure of the strategies due to uncoordinated implementation initiatives. The public sector must work together with the private sector, and individuals [15]. The challenges are attributed to; unfavorable framework conditions and weak enabling factors, lack of innovative leadership at the various levels, lack of systematic and precise use of data and measurements, little knowledge on the application of innovation methods and processes [16]. The government must understand the trends affecting innovative processes. It will help in personalizing services, responding to customer expectations, and task management among other factors [17]. More research needs to be done to comprehend and deal with the challenges. Mauritius should develop a new policy frame work for the improvement of its public service sector; this should reflect the values of inclusiveness, innovation, and transformation. The government must leverage its capacity to be innovative and facilitate concrete change processes. Although there are already strategies in place to improve the situation, more-needs to be done. It will improve its ability to deal with challenges of health care costs, social security, and public finances among others. Today, the progress must take advantage of ICT and other technological advancements.

\section{Conclusion}

Mauritius has made considerable progress towards the use of institutional innovation, inclusiveness, and transformation to improve the quality of its public service delivery. It is evident in the analysis of the current state of Mauritius' governance and public administration, and strategies already adopted to improve its state. However, more needs to be done if the country hopes to achieve its Millennium Development Goals. It creates a foundation on which various strategies can be developed and implemented. Adoption of the recommended strategies will go a long way in improving the quality of public service 
Citation: Roland G (2017) An Elaboration on Measures to Promote Institutional Innovation, Transformation, and inclusiveness to Enhance Public Service Delivery. Review Pub Administration Manag 5: 220. doi:10.4172/2315-7844.1000220

Page 4 of 4

delivery. Being aware of the barriers that may hinder implementation of the strategies will also help in avoiding or coping with them. It will improve the government's capacity to anticipate and handle a variety of challenges in today's society.

\section{References}

1. African Development Bank (2014) Mauritius: Country strategy paper 20142018, SARC Department.

2. The President of the Republic of Mauritius (2015) Achieving meaningful change. Government Program, 2015-2019.

3. Deloitte (2015) Service delivery trend outlook: the potential future of government customer service delivery. The government service thought leadership series.

4. Price Waterhouse Coopers (2013) Future of government: Tomorrow's leading public body.

5. UNDP (2015) Work in the public service of the future: Global centre for public service excellence.

6. Dukhira C (2016) A new public sector for modern Mauritius. La Sentinelle.

7. Interserve (2016) What does the future of public service delivery look like?

8. Subhash B (2014) Public service delivery: Role of information and communication technology in improving governance and development impact. Asian development bank.

9. Deloitte, Touche (2014) Public sector: Solutions to a sustainable government.

10. United Nations (2013) Governments have to use innovative means to delivery public services.

11. llott $\mathrm{O}$ (2016) Has government learned the vital lessons of public service failures? The Guardian.

12. OECD (2011) Together for better public services: partnering with citizens and civil society. ISBN: 978-9264118843.

13. Oosteron W (2007) The road ahead for public service delivery: Delivering on the customer promise. Price water house coopers. Public Sector Research Center, India.

14. Daglio M, Garson D, Kitchen H (2014) Building organizational capacity for public sector innovation. OECD conference, "Innovating the public sector: From ideas to impact." Paris.

15. Institute for Government (2015) Public service delivery at a local level.

16. Expert Group on Public Sector Innovation (2013), Powering European publicsector innovation: Towards a new architecture. European Commission, Brussels.

17. Service Futures (2015) 12 trends affecting the future of the public sector and public-sector outsourcing. 